\title{
Intermittent Claudication: The Importance of Non-Invasive Treatment in the Femoro-Popliteal Tract
}

Luigi Venturini, Daniele Ferraro and Paolo Sapienza*
Department of Surgery, Pietro Valdoni Sapienza University, Rome, Italy

\section{Commentary}

Patients affected with Peripheral arterial disease (PAD) mostly refer to physicians when Intermittent claudication (IC) occurs. Calf symptom ranging from fatigue to aching while walking is the usual clinical presentation.

The prevalence of intermittent claudication is around $4.5 \%$ in general population aged between 55 to 74 years [1]. Even if this condition has a profound and negative impact on patients' quality of life $[2,3]$, because of a sense of limitation of mobility and the fear of the progression of the disease and limb loss, patient should be reassured on the relatively benign prognosis of the pathology in case of intermittent claudication. Leng et al. [4] reported a remission of symptoms in more than $60 \%$ of the patients examined after a period of 5 years. A progression of the disease in only $25 \%$; deterioration is more likely to appear on the first year after diagnosis (7\%-9\%) compared with $2 \%$ to $3 \%$ per year thereafter [5] and can be related to poor adherence to treatments and exercise programs.

IC is more often the result of a single level stenosis or occlusion (aorto-iliac or femoro-popliteal tract). According to the Inter-society Consensus for the Management of Peripheral Arterial Disease (TASC II) the treatment for claudication, in case of femoro-popliteal involvement should focus on risk factor modification and a program of supervised exercise [5]. This approach has been validated for its efficacy and costeffectiveness by several studies [6-9]. This is not a "wait and see" approach to PAD; physicians should consider IC as the "wedge of an iceberg" of widespread atherosclerosis involving the whole cardiovascular system. At this point of the disease, the base of treatment should be pharmacological (i.e. lipid-lowering, antiplatelet, antihypertensive and blood sugar regulator drugs) associated with the correction of unhealthy habits (i.e. sedentary lifestyle, smoking habit, and obesity). An early revascularization may lead the patient to underestimate the importance of risk factor and lifestyle modification whereas exercise training under a supervised setting, increase the perception of the disease. The importance of lowering the cardiovascular risk is more evident if we consider that these patients have a significantly higher risk of mortality from cardiovascular causes when compared to the normal population (RR : $2.67, \mathrm{P} \leq 0,01)[4]$.

If the pharmacologic or risk factor correction fails, intervention has also been advocated at this stage of the disease. In particular, endovascular procedures are recommended in TASC A lesions [5]. Endovascular interventions are attractive to patients and physicians because of lower morbidity and mortality rates, but angioplasty and stinting remains a controversial issue in patients experiencing claudication, especially for the femoro-popliteal district. Endovascular procedures have clearly demonstrated their role in contemporary practice with low morbidity and mortality. Even though, while treating our patients, we should always keep in mind that any kind of revascularization may be the onset of a vicious cycle of repeated interventions 10 and that even if morbidity rates are low, they still exist $[10,11]$. This should not be underestimated when we propose invasive treatments to claudicating patients, who are affected with a mild peripheral arterial disease. Furthermore, an early endovascular approach may alter the distal arterial segments, which can be used as the distal anastomotic site for a future surgical bypass in the case of an endovascular failure [12]. These patients will be exposed to increased risks of surgical and medical complications and enormous medical costs that we can easily prevent by offering the best medical treatment and adequate encouragement for starting a supervised training program that is surely more fatiguing but at least as effective as invasive procedures $[7,8,13]$. A recent cost-analysis study estimated savings of up to 33 million euros per year if a supervised exercise training first approach for intermittent claudication is followed in the Dutch healthcare system [14].

In conclusion, at present we are convinced for an ethical and economic perspective that patients affected with IC should be treated conservatively; surgery either endovascular or open can be postponed as soon as the patients will develop significant and disabling symptoms.

\section{References}

1. Fowkes FG, Housley E, Cawood EH, Macintyre CC, Ruckley CV, et al. (1991) Edinburgh Artery Study: prevalence of asymptomatic and symptomatic peripheral artery disease in general population. Int J Epidemiol 20: 384-392.

2. Mays RJ, Casserly IP, Kohrt WM, Ho PM, Hiatt WR, et al. (2011) Assessment of functional status and quality of life in claudication. J Vasc Surg 53: 1410-1421.

3. Treat-Jacobson D, Halverson SL, Ratchford A, Regensteiner JG, Lindquist $R$ (2002) A patient-derived perspective of health-related quality of life with peripheral arterial disease. J Nurs Scholarsh 34: 55-60.

4. Leng GC, Lee AJ, Fowkes FG, Whiteman M, Dunbar J, et al. (1996) Incidence, natural history and cardiovascular events in symptomatic and asymptomatic peripheral arterial disease in the general population. Int J Epidemiol 25: 11721181.

5. Norgren L, Hiatt WR, Dormandy JA, Nehler MR, Harris KA et al. (2007) InterSociety Consensus for the Management of Peripheral Arterial Disease (TASC II). J Vasc Surg 45: S5-S67.

6. Perkins JM, Collin J, Creasy TS, Fletcher EW, Morris PJ (1996) Exercise training versus angioplasty for stable claudication: Long and medium term results of a prospective, randomized trial. Eur J Vasc Endovasc Surg 11: 409413.

7. Gommans LN, Saarloos R, Scheltinga MR, Houterman S, de Bie RA, et al (2014) Editor's choice - The effect of supervision on walking distance in patients with intermittent claudication: a meta-analysis. Eur J Vasc Endovasc Surg 48 : 169-184.

8. Treesak C, Kasemsup V, Treat-Jacobson D, Nyman JA, Hirsch AT (2004) Costeffectiveness of exercise training to improve claudication symptoms in patients with peripheral arterial disease. Vasc Med 9: 279-285.

9. Fokkenrood HJ, Bendermacher BL, Lauret GJ, Willigendael EM, Prins $\mathrm{MH}$, et al. (2013) Supervised exercise therapy versus non-supervised exercise therapy

*Corresponding author: Paolo Sapienza, MD, PhD, Department of Surgery Pietro Valdoni Sapienza University of Rome Policlinico Umberto I Viale de Policlinico, Rome, Italy; Tel. +390649972780; Fax: +390649970794; E-mail: paolo.sapienza@uniroma1.it

Received July 29, 2014; Accepted October 29, 2014; Published October 29 2014

Citation: Venturini L, Ferraro D, Sapienza P (2014) Intermittent Claudication: The Importance of Non-Invasive Treatment in the Femoro-Popliteal Tract. Surgery Curr Res 4: 207. doi:10.4172/2161-1076.1000207

Copyright: ( 2014 Venturini L, et al. This is an open-access article distributed under the terms of the Creative Commons Attribution License, which permits unrestricted use, distribution, and reproduction in any medium, provided the original author and source are credited. 
Citation: Venturini L, Ferraro D, Sapienza P (2014) Intermittent Claudication: The Importance of Non-Invasive Treatment in the Femoro-Popliteal Tract. Surgery Curr Res 4: 207. doi:10.4172/2161-1076.1000207

for intermittent claudication. Cochrane Database Syst Rev 8: CD005263.

10. Lepantälo M, Salenius JP, Albäck A, Ylönen K, Luther M (1996) Frequency of repeated vascular surgery- A survey of 7616 surgical and endovascular Finnvasc procedures, Finnvasc Study Group. Eur J Surg 162: 279-285.

11. Conrad MF, Cambria RP, Stone DH, Brewster DC, Kwolek CJ, et al. (2006) Intermediate results of percutaneous endovascular therapy of femoropopliteal occlusive disease: A contemporary series. J Vasc Surg 44:762-769.
12. Joels CS, York JW, Kalbaugh CA, Cull DL, Langan EM $3^{\text {rd }}$, et al. (2008) Surgical implications of early failed endovascular intervention of the superficial femoral artery. J Vasc Surg 47: 562-565.

13. Borghese O, Sapienza P, Venturini L, Bononi M, di Marzo L (2014) Considerations: When More is Not Necessarily Better. Vasc Endovascular Surg 19: 1538574414540343.

14. Fokkenrood HJ, Scheltinga MR, Koelemay MJ, Breek JC, Hasaart F, et al. (2014) Significant savings with a stepped care model for treatment of patients with intermittent claudication. Eur J Vasc Endovasc Surg 48:423-429. 